\title{
Impact of Emotional intelligence, cultural intelligence, Perceived organizational supporting practices and Perceived family support on cross cultural adjustment of Indian IT expatriates working in the United States of America
}

\author{
Rajeesh Viswanathan, Moiz Mohammed, N. Sarath Lal, Jahira Parveen
}

\begin{abstract}
:
Purpose - The current study intends t to examine the effects of Emotional intelligence, cultural intelligence, Perceived organizational supporting practices and Perceived family support on cross cultural adjustment of Indian IT expatriates working in the United States of America.

Design/Methodology/Approach - This study adopts positivist deductive approach it, starts with clear variables which are derived from theory and based on these variables. The data for the study was collected through the structured questionnaire.

Design/Methodology/Approach - This study adopts positivist deductive approach it, starts with clear variables which are derived from theory and these variables. The facts for the study was collected through the structured questionnaire. The sample for the present study was collected from the Indian IT expatriates who are assigned to USA working in the four major IT cluster of USA i.e. California, Washington, New York, \& Chicago. A total 634 questionnaires were received indicating a response rate of $52 \%$. The questionnaire for this research consists of 75 item. Linkerts five point scale has been used to measures ranging from strongly agree to strongly disagree. SPSS 21 and Microsoft excel are the statistical packages and regression is the tools used in the present study
\end{abstract}

Findings - A noteworthy relationship was observed among the following -emotional intelligence with cross cultural work adjustment and cross cultural general adjustment. Emotional intelligent plays a vital role in cross cultural work adjustment and cross cultural general adjust, as employee with high Emotional Intelligence can adapt to any work / cultural scenario. Expatriates culture would vary from host country culture. Emotional Intelligence can help expatriate to overcome the cultural difference. It's important since it facilitates in completion of international assignment effectively. A significant relation is found between the perceived organizational support and expatriate cross cultural work adjustment and cross cultural general adjust. The organization support in terms of financial adjustment and career support help the expatriate to adjust well in

Revised Manuscript Received on December 22, 2018.

Dr. Rajeesh Viswanathan, Asst Professor, Dept of International Business, School of Management, Pondicherry University, Pondicherry

Dr. Moiz Mohammed, Asst Professor Nawab Shah Alam Khan College of Engineering and Technology, Hyderabad, India.

N. Sarath Lal, Dept of International Business, School of Management, Pondicherry University, Pondicherry, India.

Dr. Jahira Parveen, Faculty of Management, SRM Institute of Technology, Chennai, India. the diverse culture. A significant relation between the perceived family support and cross cultural work adjustment and cross cultural general adjust. Family support plays an imperative task in the expatriate cross cultural work adjustment and cross cultural general adjust. Adjustment of the accompanying family significantly impacts the work and general adjustment of the expatriate

Originality/value - This study provides insightful findings in understanding the role individual competencies like emotional intelligence and cultural intelligence play in facilitating expatriate adjustment i.e. from family and organization support in the individual level and work outcomes. This study also shows the importance of the demographic variables with impact expatriate adjustment. In spite of the limitations of the research, the study contributed to the international human resources management by exploring the Indian IT expatriates adaptation process in the western context.

Index Terms: Emotional intelligence, Cultural intelligence, perceived organizational supporting practices, Perceived family support and cross cultural adjustment.

\section{INTRODUCTION}

This study focuses on Indian IT expatriates working in the United States of America and their experiences and perceptions of their cross-cultural adjustment. The rationale of research was to examine what are the individual level factors and organizational level factors which influence the cross cultural adjustment of the Indian IT expatriates and. It looks at how the emotional intelligence, cultural intelligence, organizational supporting practices and family support influence the job cross cultural adjustment of the expatriates. Merely selecting an employee alone does not serve the purpose today. They need to be groomed. The way the organizations do business have transformed enormously. There is increased interaction between the people from different cultures and there is high degree of global mobility. Post 1990 there is tremendous growth of the Indian MNCs which started providing software services to the clients across the globe. India due to its highly skilled human resources emerged as a major of exporter of software. India's gross export of IT \& ITES/BPO services (excluding commercial presence) during 2013-14 was estimated at

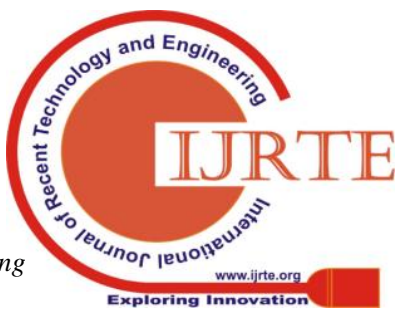


4,322.8 billion (US\$ 71.4 billion), exhibiting 14.1 per cent growth in US \$ terms over the preceding year (RBI 2015). 'It was observed that USA \& Canada' was the top destination for software exports and accounted for 62.7 per cent in total export of software services during 2013-14 (RBI 2015). European countries had 24.4 per cent share, of which UK accounted for 12.6 per cent. The percentage of software services exports from India through Mode-1 (cross-border supply) and Mode-2 (consumption abroad) came down whereas through Mode-3 \& 4 (commercial presence) and (presence of natural person) enhanced in 2013-14. It was observed that software exports by other affiliate stood at 689.0 billion (US\$ 11.4 billion) in 2013-14 and total international trade in IT services by India, including the services delivered by foreign affiliates, stood at`5,011.8 billion (US $\$ 82.8$ billion) in 2013-14.Due to this tremendous growth, the Indian MNCs started sending the employees to the client sites to cater to the global business needs.

In the recent literature on the expatriates cross cultural adjustment and performance, much prominence is given to the role emotional intelligence. Emotional intelligence can be defined as "The potential to infer and manage the emotional reactions of self and of others and further to adapt to different scenarios was highly recognized especially in different cultural settings(Lin, Chen, \& Song, 2012:542). "The potential to monitor one's emotional changes and precisely understand the emotional reactions of others is called emotional intelligence." (Lin, Chen, \& Song, 2012: 542).There is enough evidence that emotional intelligence play an important role in the various facets of employee's work. The emotional intelligence assumes a significant role in the international assignments because of the nature of the international assignments. When an employee is selected and assigned to an international assignment, he or she face new culture, and new work practices which might cause significant problems to the international assignee to get adjusted to the new environment and it also will have a significant effect on the performance level of the employee. Under such instances "EI with its Dimensions are critical factors that facilitate adjustment when facing a different cultural environment." (Lin, Chen, \& Song, 2012: 545). Also (Lin, Chen, \& Song, 2012: 544) argues that "EI and its dimensions as a predictor of cross-cultural adjustment." The present study is an attempt to examine the effects of emotional intelligence on cross cultural adjustment, psychological wellbeing, Intention to finish the assignment and expatriate job performance.

One of the important ability to be successful in the globalized world is the ability to interact with people from different cultures. The importance of the cultural intelligence has grown enormously because of the diversity in work force and because of the increase in international mobility due to globalization. An expatriate may faces number of problems when working in a culturally diverse country and workplace. In order to cope up with such problems and adjust successfully the expatriate needs certain abilities. "CQ refers to the ability to collect and process messages, to make decisions, and the relative approaches needed in order to adjust to a new environment." (Lin, Chen, \& Song, 2012:542). "Cultural intelligence refers to individual capacities which enable one to interact effectively with others from different cultural backgrounds and in different cultural contexts" (MacNab \& Worthley, 2012:63). "Earley and colleagues developed a three-part model of cultural intelligence with cognitive/meta-cognitive, motivation, and behavior components" as cited in (MacNab \& Worthley, 2012). "Cultural intelligence [cultural quotient (CQ)] is the ability of individuals to acquire, store, and use cultural knowledge" as cited in (Wua \& Ang, 2011: 2684). (Lin, Chen, \& Song, 2012: 542) acknowledged the need to increase an individual's CQ and EI to increase their adjustment to work, their interactions with host nationals, and their ability to deal with general living conditions in a cross-cultural context. "Cultural Intelligence is one of the key determinates of expatiate success" (Lin, Chen, \& Song, 2012: 542) \& (Wua \& Ang, 2011: 2684).Expatriates who have to work in the culturally diversified workforce and country have to develop this special skill to be better adjusted and more productive. The present study is an attempt to examine the effects of cultural intelligence on cross cultural adjustment, psychological wellbeing, Intention to finish the assignment and expatriate job performance.

"POS mentions they way organization intends to compensate employees for the services rendered and also the interesting work assignments, conducive working conditions being provided" as cited in (Erturk \& Vurgun, 2015:37). "its learned that employees are more inclined to repay when they receive high support Their involvement will be continuous (Erturk \& Vurgun, 2015:37).The importance of the organizational support is essential for the employee well-being and the employees if they perceive that organization supports them in all facets of their work and family they will to be more productive and more committed to the organization. The support of the organization becomes more relevant in the instance of the expatriates because the expatriates are working away from the parent organization in culturally diverse settings. "Expatriate supporting practices typically include a series of human resource supporting practices in international assignments, we recognize those supporting practices as a bundle, as suggested by prior research in the human resource management literature" as cited in (Wua \& Ang, 2011: 2684).Therefore, this study also focuses on the expatriate supporting practices as perceived by the employees. The present study is an attempt to examine the effects of Perceived organizational supporting practices on cross cultural adjustment, psychological wellbeing, Intention to finish the assignment and expatriate job performance.

"Expatriate assignments has two issues one moving with families to new location or being away from the family." (Hechnova, Beehr, \& Christiansen, 2003). "Expatriate adjustment has been strongly related to non-work factors such as psychological orientations, attitudes towards international living and family-related problems" (Osman-Gani \& Rockstuhl, 2009:279). The expatriate cross cultural adjustment largely depends on the family support and the social support in the host country. The present study is an attempt to examine the effects of Perceived family support on cross cultural adjustment, psychological wellbeing, Intention to finish the assignment and expatriate job performance. Failure may resulting in damaging company's important constituents-local national employees, host government officials, local suppliers, customers, and communities" as cited in (Hechnova, Beehr, \& Christiansen, 2003).

(Lin, Chen, \& Song, 2012: 542) argue that "cross cultural adjustment is extremely challenging and firms are 
focusing on technical expertise rather than cross cultural competence" as cited in (Wua \& Ang, 2011: 2684). As a result, the employees who are not culturally competent to adjust to culturally diversified work settings face problems in adjustment and job performance. (Lin, Chen, \& Song, 2012:542) argue that "Good adjustment will enhance life satisfaction and performance and "cultural sensitivity plays a major role in expatriate adjustment and performance" (Wua \& Ang, 2011: 2684). " Research also supports the concept that psychological stress resulting from poor adjustment has a strong effect on poor performance and job dissatisfaction." as cited in (Lin, Chen, \& Song, 2012: 542) and "Failure to adjust well to the new environment could lead to avoidance or withdrawal symptoms, all of which would threaten the new expatriate assignment and eventual work performance" as cited in (Wua \& Ang, 2011: 2685).

\section{PuRPose OF THE STUdY}

The present study is an attempt to examine the effects of emotional intelligence, cultural intelligence, perceived organizational supporting practices and perceived family support on cross cultural adjustment of Indian IT expatriates working in the United States of America.

\section{RATIONALE}

When an expatriate is assigned to country with is culturally different the expatiate employee may experience cultural difference and this may impact his adjustment to the new environment. Number of MNCs operating in India sends the employee to the oversea assignments for the undertaking projects. Therefore, there is a need to study the impact of individual level competencies emotional intelligence, cultural intelligence, perceived organizational supporting practices and perceived family support which impact the cross cultural adjustment of Indian expatriates working in culturally diverse country like United States of America. This aim of the study is to provide into insights that will help the MNCs in selection and training expatiates.

\section{SIGNIFICANCE OF THE STUDY}

On a general level, this study will have significant value for Indian expatriates investing time in United States of America, because this research thoroughly covers past and present cultural and business analysis trends in Saudi Arabia.

1. The findings of this study will provide valuable information for policy makers in the top management of Indian companies to make effective decisions that support and fund effective expatriation programs.

2. This study and its findings will also update international research on Indian expatriation and cross-cultural adjustment

\section{SCOPE OF THE Present STUdY}

This study is confined to the IT industries and the respondents are the Information Technology expatriates assigned to United States of America on short time and long term assignments on client side or in subsidiary offices of the MNC. Impact of individual level competencies emotional intelligence, cultural intelligence, perceived organizational supporting practices and perceived family support on the cross cultural adjustment. Hence, the study is confined to the study variables only.

\section{RATIONALE}

When an expatriate is assigned to country with is culturally different the expatiate employee may experience cultural difference and this may impact his adjustment to the new environment. Number of MNCs operating in India sends the employee to the oversea assignments for the undertaking projects. Therefore, there is a need to study the impact of individual level competencies emotional intelligence, cultural intelligence, perceived organizational supporting practices and perceived family support which impact the cross cultural adjustment of Indian expatriates working in culturally diverse country like United States of America. This aim of the study is to provide into insights that will help the MNCs in selection and training expatiates.

\section{SIGNIFICANCE OF THE STUDY}

On a general level, this study will have significant value for Indian expatriates investing time in United States of America, because this research thoroughly covers past and present cultural and business analysis trends in Saudi Arabia.

1. The findings of this study will provide valuable information for policy makers in the top management of Indian companies to make effective decisions that support and fund effective expatriation programs.

2. This study and its findings will also update international research on Indian expatriation and cross-cultural adjustment

\section{SCOPE OF THE PRESENT STUdy}

This study is confined to the IT industries and the respondents are the Information Technology expatriates assigned to United States of America on short time and long term assignments on client side or in subsidiary offices of the MNC. Impact of individual level competencies emotional intelligence, cultural intelligence, perceived organizational supporting practices and perceived family support on the cross cultural adjustment. Hence, the study is confined to the study variables only.

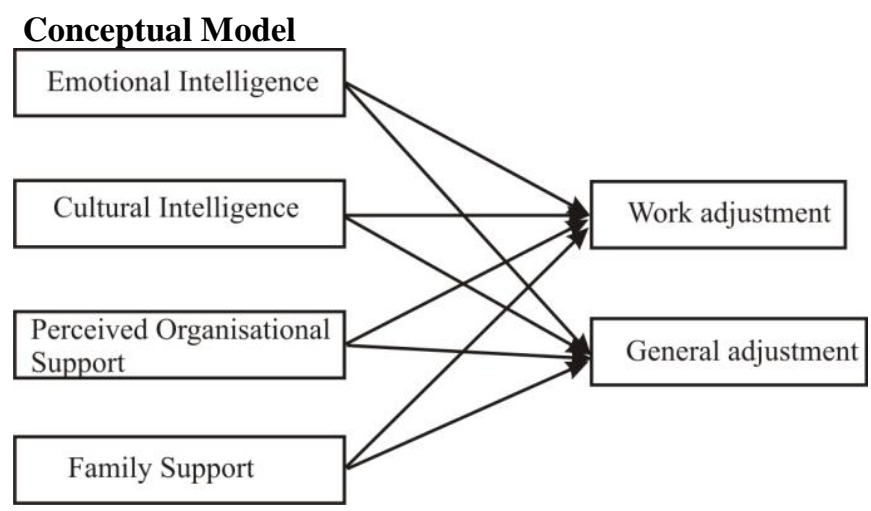

\section{Objectives}

- To understand the relationship of emotional intelligence, cultural intelligence, perceived organizational support, perceived family support with cultural work adjustment of Indian Information technology expatriates in United States of America.

- To understand the relationship of emotional intelligence, cultural intelligence, perceived organizational support, perceived family support with cultural General adjustment of Indian Information technology expatriates in United States of America.

\section{Hypothesis Development}

H1: There exist no significant relationship between emotional intelligence, and expatriate cross-cultural work adjustment.

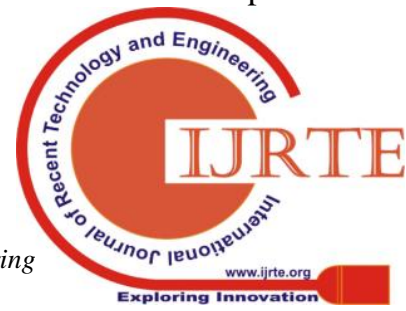


H2: There exist no significant relationship between cultural intelligence and expatriate cross-cultural work adjustment.

H3: There exist no significant relationship between perceived organizational support and expatriate cross-cultural work adjustment.

H4: There exist no significant relationship between perceived family support and Intention to finish the assignment.

H5: There exist no significant relationship between emotional intelligence, and expatriate cross-cultural general adjustment.

H6: There exist no significant relationship between cultural intelligence and expatriate cross-cultural general adjustment.

H7: There exist no significant relationship between perceived organizational support and expatriate cross-cultural general adjustment.

H8: There exist no significant relationship between perceived family support and expatriate cross-cultural general adjustment.

\section{Research Design}

This study adopts positivist deductive approach it, starts with clear variables which are derived from theory and based on these variables, testable hypothesis were framed and tested. This study uses quantitative approach since all the variables in the study are quantifiable. The data for the study was collected through the structured questionnaire. The research intends to contribute to the literature on expatriate management and international human resource management in general. This study is descriptive in nature. The aim of the study is to find causes and relationships between the variables of interest. The study addresses the descriptive to what extent? Since the study involves larger samples, primary data was collected by using survey method. The objective is to understand the perceived impact of emotional intelligence, cultural intelligence, perceived organizational support, perceived family support on cross cultural adjustment of the expatriates. In order to fulfil the study objectives the study employed appropriate methodology.

\section{Survey Method}

Surveys refer to the method of data collection that utilizes questionnaires or interview techniques for recording the verbal behaviour of respondents (Ghauri \& Gronhaug, 2005).A survey is way to collect data from a range of respondents by asking them questions (Maylor \& Blackmon, 2005). (Zikmund, 2003) defined survey "as a method of gathering primary data based on communication with a representative sample of individuals." A survey is a measurement process used to collect information during a highly structures interview-sometimes with a human interviewer and other times without (Cooper \& Schindler, 2006).Surveys require asking people, who are called respondents, for information, using either verbal or written questions (Zikmund, 2003).Surveys are especially useful for capturing facts, opinions, behaviors, or attitudes (Maylor \& Blackmon, 2005).Questionnaires, structures interviews are most commonly used tools in survey research design (Maylor \& Blackmon, 2005). Surveys can be quick, inexpensive, efficient, and accurate means of assessing information about the population (Zikmund, 2003). Survey can be useful especially when we want to collect data from a large number of respondents and have limited time for collecting data and when the respondent cannot be reached directly (Maylor \& Blackmon, 2005). Due to the usefulness of survey method and also based on the previous studies this study adopted survey method to collect the data( see Harrison, \& Shaffer, 2007; Shaffer, Kraimer, Chen, Bolino, \& Chen, 2012). Majority of the researchers used the survey method to carry out the research in cross culturalt context. Therfore this study used survey method to carry out research.

\section{Population and Sample}

The sample for the current study includes Indian expatriates who have their parent company in India and posted either at a client site or a branch office in United States of America. In the present study, Indian IT expatriates assigned on the international assignments to United States of America form the sample unit. The sampling technique used for this study is Multistage Random Sampling method (Kothari C.R., 2004).

The sample for the present study was collected from the Indian IT expatriates who are assigned to USA working in the four major IT cluster of USA i.e. California, Washington, New York, \& Chicago. These four states were selected as they were considered the largest IT clusters by the U.S. Cluster Mapping Project. The HR managers of the companies operating in these four regions were approached using networks of the researcher and questionnaires were handed over to the HR managers to be distributed to the Indian IT employees who assigned to the international assignment. The HR managers distributed the questionnaires and collected data and the research collected back the questionnaires from the HR managers of the companies. A total 1200 questionnaires were distributed among the four IT clusters (300 hundred in each cluster) accompanied by a letter emphasizing the confidentiality and anonymity of responses. A total 634 questionnaires were received indicating a response rate of $52 \%$ which is considered a good response rate due to the nature of the study. Out of the 634 questionnaires, received 111 questionnaires were discarded due to missing data. 525 questionnaires were used for the final study. From this a total sample of 188 females (40 percent) and 282 males (60 percent). Ofwhich average age of employee was 32 years with minimum qualification of undergraduate (bachelors) degree possessing work experience ranged from 05 to 10 years with the average of 07 years.

Descriptive and analytical research design is used and data were collected from 523 IT expatriates working in USA through structured questionnaire.

\section{Research Tools and Software Package Used}

Research tools are statistical methods used for data analysis and to arrive substantial inferences. SPSS 21, Microsoft Excel are the statistical packages used in the present study and the following tools were applied to analyze the data.

\section{Measures}

Cross cultural adjustment: Cross cultural adjustment was measure by 10 item work adjustment scale and 9 item general adjustment scale developed by Yu-Ping Chen which was modified and adopted from Black and Stephens, 1989 and Thomas \& Lazarova, 2006. The participants were asked to rate each item on a 5 pointLikert scale from 1(strongly disagree) to 5 (strongly agree). In the current sample, the 
Cronbach alpha for the instrument was 0.934 for work adjustment and 0.919 for general adjustment

Emotional intelligence :The scale developed by Wong, C. S., \& Law, K. S. (2002) comprising of 16 item were used. It is a 16 item instrument and assesses four dimensions, namely self-emotional appraisal, others emotional appraisal, use of emotions, and regulation of emotions. Employees had to put their views in 5 point- Likert scale from 1(strongly disagree) to 5 (strongly agree). If the scores were high it showed there is indicated higher cultural intelligence. In the current sample, the Cronbach alpha for the current research instrument was 0.969

Cultural intelligence: Cultural intelligence was measured by 20 item Cultural Intelligence Scale developed by Ang et al. (2007).It is a 20 -item instrument and assesses four dimensions, namely cognitive dimension, meta cognitive dimension, behavioral dimension and motivational dimension of cultural intelligence. Employees had to rate on a 5 point- Likert Scale from 1(strongly disagree) to 5 (strongly agree). Higher scores indicated higher cultural intelligence. In the current sample, the Cronbach alpha for the instrument was 0.977

Perceived organizational support: Perceived organizational support was measured with 12 items scale developed by (Kraimer \& Wayne, 2004). It is a 12 -item instrument and assesses three dimensions namely financial support, career support, and adjustment support. Respondents had to rate on a 5 point- Likert scale from 1(strongly disagree) to 5 (Strongly agree). Higher scores indicated higher cultural intelligence. In the current sample, the Cronbach alpha for the instrument was 0.968

Perceived family support: The spousal social support was measured with 8 items scale developed by (Vinokur and van Ryn, 1993). The 8 -item scale measure the perceived family/spousal support during the international assignment. Respondents had to rate on a 5 point- Likert scale from 1(strongly disagree) to 5 (strongly agree). In the current sample, the Cronbach alpha for the instrument was 0.933

\section{Pilot study}

Pilot testing of the questionnaire was done with Indian IT expatriates those who are working in the United States of America before carrying out the main study. This was to ensure correction of any ambiguities in the measurements as well as capturing correctly the concepts used in the study. Conducting the pilot study the following changes were made to make the questionnaire more understandable and purposeful. Based on the feedback given by the respondents, minor corrections are made in the questionnaire.

\section{Reliability and Validity}

Reliability is the ratio of true variance to the total variance yielded by the measuring instrument. It indicates stability and the internal consistency of a test. The reliability of a measure indicates the stability and consistency with which the instrument measures the concept and helps to assess the 'goodness' of a measure. A measure is reliable to the degree that it supplier consistent results. Validity could be defined as the extent to which the set of measures represent the concept of the study and the degree to which it is free from any random error (Hair, Black, Babin, \&Anderson, 2010). Validity testing refers to as testing the ability of the instrument to measure the particular construct.

\begin{tabular}{|c|l|c|c|c|c|}
\hline $\begin{array}{c}\text { S. } \\
\text { No }\end{array}$ & \multicolumn{1}{|c|}{ Construct } & $\begin{array}{c}\text { No of } \\
\text { Items }\end{array}$ & $\begin{array}{c}\text { Reliability } \\
\text { (Cronbach's alpha) }\end{array}$ & $\begin{array}{c}\text { Composite } \\
\text { Reliability }\end{array}$ & AVE \\
\hline 1 & Emotional Intelligence & 16 & 0.969 & 0.972 & 0.686 \\
\hline 2 & Cultural Intelligence & 20 & 0.977 & 0.979 & 0.700 \\
\hline 3 & $\begin{array}{l}\text { Perceived organizational } \\
\text { supporting practices }\end{array}$ & 12 & 0.968 & 0.972 & 0.742 \\
\hline 4 & Perceived family support & 8 & 0.933 & 0.946 & 0.748 \\
\hline 5 & Work Adjustment & 10 & 0.934 & 0.944 & 0.629 \\
\hline 6 & General Adjustment & 9 & 0.919 & 0.933 & 0.608 \\
\hline
\end{tabular}

The above table displays the value of Cronbach's Alpha coefficient of all the variables in the study of Indian IT expatriates in United States of America. The overall Cronbach's Alpha coefficient is 0.975, which indicates the high reliability of data. Validity is measured by Average Variance Extracted (AVE). The constructs with has AVE value of above 0.50 possesses convergent validity. In the above table, it can be clearly seen that the AVE values of all the constructs are above 0.50

\section{Normality}

Larger deviations of data form normal distribution affects the results and all the resulting statistics become invalid(Hair, Black, Babin, \& Anderson, 2010). Hence, it is important to test the normality of the data. Normality test are used to check whether the data set is normally distributed. A common rule of normality test is to get the skewness and kurtosis of the data. Skewness instrument is used in distribution analysis as a sign of asymmetry and deviation from a normal distribution. Skewness is the extent to which a variable's distribution is symmetrically around its mean value. If the data is normally distributes the values of skewness should fall within +2 to -2 range. Kurtosis instrument is used in distribution analysis as a sign of flattening of a distribution. Kurtosis is a measure of whether the distribution is too peaked. The values of kurtosis also should fall within +2 to -2 range when the data are normally distributed.

\begin{tabular}{|c|c|c|c|}
\hline \multicolumn{4}{|c|}{ Skewness and kurtosis } \\
\hline \multicolumn{4}{|c|}{ Descriptive Statistics } \\
\hline & $\mathrm{N}$ & Skewness & Kurtosis \\
\hline & Statistic & Statistic & Statistic \\
\hline Emotional Intelligence & 523 & -0.243 & -1.601 \\
\hline Cultural Intelligence & 523 & -0.081 & -1.719 \\
\hline $\begin{array}{l}\text { Perceived } \\
\text { Organizational Support }\end{array}$ & 523 & -0.265 & -1.661 \\
\hline $\begin{array}{l}\text { Perceived Family } \\
\text { Support }\end{array}$ & 523 & -0.232 & -1.549 \\
\hline Work Adjustment & 523 & -0.575 & -1.222 \\
\hline General Adjustment & 523 & -0.431 & -1.505 \\
\hline
\end{tabular}

\section{Multiple Regression Model}

A multiple regression model for work adjustment of the Indian IT expatriates was developed with various factors like emotional intelligence, cultural intelligence, perceived organizational support, perceived family support as predictors of work adjustment.

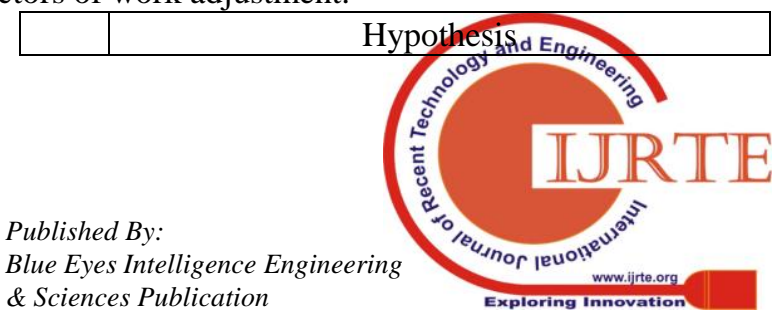


Impact of Emotional intelligence, cultural intelligence, Perceived organizational supporting practices and Perceived family support on cross cultural adjustment of Indian IT expatriates working in the United States of America

\begin{tabular}{|l|l|}
\hline H1 & $\begin{array}{l}\text { There exist is no significant relationship } \\
\text { between emotional intelligence, and } \\
\text { expatriate cross-cultural work adjustment. }\end{array}$ \\
\hline H2 & $\begin{array}{l}\text { Significant relationship between cultural } \\
\text { intelligence and expatriate cross-cultural } \\
\text { work adjustment is not there. }\end{array}$ \\
\hline H3 & $\begin{array}{l}\text { There is no significant relationship between } \\
\text { perceived organizational support and } \\
\text { expatriate cross-cultural work adjustment. }\end{array}$ \\
\hline H4 & $\begin{array}{l}\text { There is no significant relationship between } \\
\text { perceived family support and Intention to } \\
\text { cross-cultural work adjustment. }\end{array}$ \\
\hline
\end{tabular}

\section{Model Summary}

\section{Model Summary}

\begin{tabular}{|c|c|c|c|c|}
\hline Model & $\mathrm{R}$ & $\mathrm{R}$ Square & $\begin{array}{c}\text { Adjusted R } \\
\text { Square }\end{array}$ & $\begin{array}{c}\text { Std. Error of the } \\
\text { Estimate }\end{array}$ \\
\hline 1 & $.630^{\mathrm{a}}$ & .396 & .392 & .4314 \\
\hline
\end{tabular}

a. Predictors: (Constant), Perceived Family Support, Perceived Organisational Support, Cultural Intelligence, Emotional Intelligence

\section{Interpretations:}

$\mathrm{R}$ is the correlation, its value is 0.630 and $\mathrm{R}$ square is the degree of determination, its value is 0.396 . The degree of determination show the extent to which emotional intelligence, cultural intelligence, perceived organizational support, perceived family support influence work adjustment. Here the work adjustment is determined to an extent of $39 \%$ by emotional intelligence, cultural intelligence, perceived organizational support, and perceived family support

\section{Anova Table:}

\begin{tabular}{|c|c|c|c|c|c|}
\hline \multicolumn{6}{|c|}{ ANOVA $^{2}$} \\
\hline Mbdel & $\begin{array}{l}\text { Sum of } \\
\text { Squares }\end{array}$ & $\mathrm{df}$ & $\begin{array}{l}\text { Mean } \\
\text { Square }\end{array}$ & $\bar{F}$ & Sig. \\
\hline Regression & 63.286 & 4 & 15.821 & 85.005 & $.000^{6}$ \\
\hline 1 Residual & 96.411 & 518 & .186 & & \\
\hline Total & 159.697 & 522 & & & \\
\hline
\end{tabular}

ANOVA table shows that the significant value is less than 0.01 , which means the dependent variable that is work adjustment is significantly predicted by the independent variables namely emotional intelligence, cultural intelligence, perceived organizational support, perceived family support at 99\% confidence level

\begin{tabular}{|c|c|c|c|c|c|c|}
\hline \multicolumn{7}{|c|}{ Coefficients $s^{2}$} \\
\hline & \multirow[t]{2}{*}{ Model } & \multicolumn{2}{|c|}{$\begin{array}{c}\text { Unstandardized } \\
\text { Coefficients }\end{array}$} & \multirow{2}{*}{$\begin{array}{c}\begin{array}{c}\text { Standardized } \\
\text { Coefficients }\end{array} \\
\text { Beta }\end{array}$} & \multirow[t]{2}{*}{$t$} & \multirow[t]{2}{*}{ Sig. } \\
\hline & & B & Std. Error & & & \\
\hline \multirow{5}{*}{1} & (Constant) & 1.811 & .124 & & 14.570 & .000 \\
\hline & Emotional Intelligence & .189 & .027 & .276 & 6.920 & .000 \\
\hline & Cultural Intelligence & .158 & .025 & .244 & 6.270 & .000 \\
\hline & $\begin{array}{l}\text { Perceived Organisational } \\
\text { Support }\end{array}$ & .178 & .026 & .284 & 6.882 & .000 \\
\hline & $\begin{array}{l}\text { Perceived Family } \\
\text { Support }\end{array}$ & -.013 & .021 & -.023 & -.650 & .516 \\
\hline
\end{tabular}

a. Dependent Variable: Work Adjustment

Work adjustment=1.811+0.189(Emotional Intelligence) +0.158 (Cultural Intelligence)

+0.178 (Perceived organisational support)- 0.013 (Perceived family support)

Among the above four factors perceived organizational support have the highest impact on the work adjustment of the Indian IT expatriates in USA. Emotional intelligence is also having significant impacting the work adjustment of the IT expatriates in USA followed by cultural intelligence. According to the model, perceived family support is not having significant impact on the work adjustment of the Indian IT expatriates in United States of America. According to the model hypothesis [H1] is rejected and it shows that there is a significant relationship between emotional intelligence, and expatriate cross-cultural work adjustment. Hypothesis [H2] is rejected and which shows that there is a significant relationship between cultural intelligence and expatriate cross-cultural work adjustment. Hypothesis [H3] is also rejected and shows that there is a significant relationship between perceived organizational support and expatriate cross-cultural work adjustment. This model accepts hypothesis [H4] and shows that there is no significant relationship between perceived family support and cross-cultural work adjustment.

General Adjustment predicated by emotional intelligence, cultural intelligence, perceived organizational support, perceived family support.

\begin{tabular}{|l|l|}
\hline H5 & $\begin{array}{l}\text { Hypothesis } \\
\text { between emotional intelligence, and } \\
\text { expatriate cross-cultural general } \\
\text { adjustment. }\end{array}$ \\
\hline H6 & $\begin{array}{l}\text { There is no significant relationship } \\
\text { between cultural intelligence and } \\
\text { expatriate cross-cultural general } \\
\text { adjustment. }\end{array}$ \\
\hline H7 & $\begin{array}{l}\text { There is no significant relationship } \\
\text { between perceived organizational } \\
\text { support and expatriate cross-cultural } \\
\text { general adjustment. }\end{array}$ \\
\hline H8 & $\begin{array}{l}\text { There is no significant relationship } \\
\text { between perceived family support and } \\
\text { expatriate cross-cultural general } \\
\text { adjustment. }\end{array}$ \\
\hline
\end{tabular}

\section{Model Summary}

Model Summary

\begin{tabular}{|c|c|c|c|c|}
\hline Model & R & R Square & $\begin{array}{c}\text { Adjusted R } \\
\text { Square }\end{array}$ & $\begin{array}{c}\text { Std. Error of } \\
\text { the Estimate }\end{array}$ \\
\hline 1 & $.721^{2}$ & .520 & .517 & .4265 \\
\hline
\end{tabular}
Perceived Organisational Support, Cultural Intelligence,
Emotional Intelligence

\section{Interpretations:}

$\mathrm{R}$ is the correlation, its value is 0.721 and $\mathrm{R}$ square is the degree of determination, its value is 0.520 . The degree of determination show the extent to which emotional intelligence, cultural intelligence, perceived organizational support, perceived family support influence Work Adjustment. Here the general adjustment is determined to an extent of $52 \%$ by emotional intelligence, cultural intelligence, perceived organizational support, and perceived family support

\section{Anova Table}


ANOVA $^{2}$

\begin{tabular}{|c|c|c|c|c|c|}
\hline Model & $\begin{array}{l}\text { Sum of } \\
\text { Squares }\end{array}$ & df & Mean Square & F & Sig. \\
\hline $\begin{array}{l}\text { Regression } \\
\text { Residual } \\
\text { Total }\end{array}$ & $\begin{array}{c}102.199 \\
94.244 \\
196.443\end{array}$ & $\begin{array}{c}4 \\
518 \\
522\end{array}$ & $\begin{array}{c}25.550 \\
.182\end{array}$ & 140.432 & $.000^{5}$ \\
\hline
\end{tabular}

a. Dependent Variable: General Adjustment

b. Predictors: (Constant), Perceived Family Support, Perceived Organisational Support, Cultural Intelligence, Emotional Intelligence

ANOVA table shows that the significant value is less than 0.01 , which means the dependent variable that is general adjustment is significantly predicted by the independent variables namely emotional intelligence, cultural intelligence, perceived organizational support, perceived family support at 99\% confidence level.

Coefficients $^{2}$

\begin{tabular}{|l|c|c|c|c|c|}
\hline \multirow{2}{*}{ Model } & \multicolumn{2}{|c|}{$\begin{array}{c}\text { Unstandardized } \\
\text { Coefficients }\end{array}$} & $\begin{array}{c}\text { Standardized } \\
\text { Coefficients }\end{array}$ & \multirow{2}{*}{ Sig. } & \\
\cline { 2 - 4 } & $\mathrm{B}$ & Std. Error & Beta & & \\
\hline (Constant) & .812 & .123 & & 6.608 & .000 \\
Emotional Intelligence & .225 & .027 & .296 & 8.345 & .000 \\
Cultural Intelligence & .200 & .025 & .277 & 8.003 & .000 \\
Perceived Organisationat & .213 & .026 & .306 & 8.330 & .000 \\
Support Family & .078 & .020 & .118 & 3.815 & .000 \\
Perceived & & & & & \\
Support & & & & \\
\hline
\end{tabular}

a. Dependent Variable: General Adjustment

GeneralAdjustment

\section{$=0.812+0.225$ (Emotionallintelligence) +0.200 (culturallintelligence) \\ +0.213 (Perceivedorganisationalsipport) +0.078 (Perceivedf amilysupport)}

Among the above four factors emotional intelligence have the highest impact on the general adjustment of the Indian IT expatriates in United States of America. Perceived organizational support is also having significant impacting the general adjustment of the IT expatriates in United States of America followed by cultural intelligence. According to the model, perceived family support is also having significant impact on the general adjustment of the Indian IT expatriates in United States of America. According to the model hypothesis [H5] is rejected and it shows that there is a significant relationship between emotional intelligence, and expatriate cross-cultural general adjustment. Hypothesis [H6] is rejected and shows that there is a significant relationship between cultural intelligence and expatriate cross-cultural general adjustment. Hypothesis [H7] is rejected and shows that is a significant relationship between perceived organizational support and expatriate cross-cultural general adjustment. Hypothesis [H8] is rejected and shows that there is a significant relationship between perceived family support and expatriate cross-cultural general adjustment.

\section{Findings}

Objective I:

To understand the relationship of emotional intelligence, cultural intelligence, perceived organizational support, perceived family support with cultural work adjustment of Indian Information technology expatriates in United States of America.

\begin{tabular}{|l|l|c|}
\hline & \multicolumn{1}{|c|}{ Hypothesis } & Result \\
\hline H1 & $\begin{array}{l}\text { There is no significant relationship between } \\
\text { emotional intelligence, and expatriate cross-cultural } \\
\text { work adjustment. }\end{array}$ & Rejected \\
\hline H2 & $\begin{array}{l}\text { There is no significant relationship between cultural } \\
\text { intelligence and expatriate cross-cultural work } \\
\text { adjustment. }\end{array}$ & Rejected \\
\hline H3 & $\begin{array}{l}\text { There is no significant relationship between } \\
\text { perceived organizational support and expatriate } \\
\text { cross-cultural work adjustment. }\end{array}$ & Rejected \\
\hline
\end{tabular}

A significant relationship was found between emotional intelligence and cross cultural work adjustment. Emotional intelligent plays a vital role in cross cultural work adjustment, as employee with high Emotional Intelligence can adapt to any work / cultural scenario. Expatriates culture would vary from host country culture. Emotional Intelligence can help expatriate to overcome the cultural difference. It's important since it facilitates in completion of international assignment effectively. A significant relation is found between the perceived organizational support and expatriate cross cultural work adjustment. The organization support in terms of financial adjustment and career support help the expatriate to adjust well in the diverse culture. A significant relations between the perceived family support and cross cultural work adjustment. Family support plays an important role in the expatriate cross cultural work adjustment. Adjustment of the accompanying family significantly impacts the work adjustment of the expatriate

\section{Objective II:}

To understand the relationship of emotional intelligence, cultural intelligence, perceived organizational support, perceived family support with cultural General adjustment of Indian Information technology expatriates in United States of America.

\begin{tabular}{|c|c|c|}
\hline & Hypothesis & Result \\
\hline $\begin{array}{l}\text { H } \\
5\end{array}$ & $\begin{array}{l}\text { There is no significant relationship } \\
\text { between emotional intelligence, and } \\
\text { expatriate cross-cultural general } \\
\text { adjustment. }\end{array}$ & Rejected \\
\hline $\begin{array}{l}\text { H } \\
6\end{array}$ & $\begin{array}{l}\text { There is no significant relationship } \\
\text { between cultural intelligence and } \\
\text { expatriate } \\
\text { adjustment. }\end{array}$ & Rejected \\
\hline $\begin{array}{l}\text { H } \\
7\end{array}$ & $\begin{array}{l}\text { There is no significant relationship } \\
\text { between perceived organizational support } \\
\text { and expatriate cross-cultural general } \\
\text { adjustment. }\end{array}$ & Rejected \\
\hline $\begin{array}{l}\text { H } \\
8\end{array}$ & $\begin{array}{l}\text { There is no significant relationship } \\
\text { between perceived family support and } \\
\text { expatriate cross-cultural general } \\
\text { adjustment. }\end{array}$ & Rejected \\
\hline
\end{tabular}

A significant relationship was found between emotional intelligence and cross cultural general adjustment. A significant relationship was found between cultural intelligence and cross cultural general adjustment. Cultural intelligence can be very useful in expatriate cross cultural adjustment. The cultural intelligence helps the expatriates to adopt cultural related behaviour's which will help the expatriate to adjust well to the new culture. A significant relationship was found between perceived organizational support and expatriate cross-cultural general adjustment. A significant relationship was found between perceived family \$upport and expatriate cross-cultural general adjustment. A \$ignificant relationship was found between perceived family \$upport and cross cultural adjustment. Family support plays an important role in the expatriate cross cultural adjustment. Adjustment of the accompanying family significantly impacts the adjustment of the expatriate Contribution of the Study 
Majority of the previous studies in the domain of expatriate management have been conducted on the western expatiates who were sent to developing countries as expatriates to work on international assignments. This study contributes to field of international human resources management and expatriate management by focusing on the Indian IT expatriates who are sent on international assignment to the developed country i.e. United States of America. This study provides insights on cross cultural adjustment and work performance in cross cultural settings. The MNCs can adopt appropriate strategies to recruit work force which is more compatible to the cross cultural settings and develop global mobile work force, ready to take on international assignment at the short notice which will give comparative advantage to these MNCs. This study gives suggestions to the MNC operating in India strategies for selecting employees who might be sent to work on international assignments. It would help in identifying the right employee for the right assignment and groom them to be successful and effective on the international assignment. This study suggests that the individuals with high levels of cultural intelligence are easily adjusted to the cross cultural setting and they are more capable to overcome cultural barriers. One of the important strategy of the MNCs is to select the candidate for international assignment who has high levels of cultural intelligence.

\section{Implications and Suggestions}

The study of emotional intelligence is gaining popularity in management literature because of its significant contributions to the managerial effectiveness. In cross cultural context emotional intelligence is being perceived as the most important element in an employee's success. Goleman suggest that while $20 \%$ of success contributed by Intelligence quotient, the remaining 80 percent success is determined by emotional intelligence as cited in (Prasad, 2006: 158). According to (Subba, 2010) it takes more than technical skill to be successful. Emotional intelligence or the ability to restrain negative feelings and to focus on the positive ones is key determinants to the individual's career success. Judicious application of emotional intelligence can lead to management development, team effectiveness. This study have empirically show evidence that indeed emotional intelligence play an important role in the cross cultural adjustment, work performance and intention to finish the assignment. It is also showed evidence that emotional intelligence on an employee help in psychological wellbeing in the cross cultural context.

Culture is fundamental to differences in business around the world. Managers can make numerous pitfalls associated with culture. However, Managers who analyze cultural in different societies in which they operate are more likely to be successful. The major frameworks can be used to help one understand cultural settings. These frameworks (Kluckhon and Strodtbeck, Hofstede, Trompenaars, and globe) each approach the domain of culture slightly differently, but they all have the potential to help business persons clearly understand the environment in which they are operating (Ahlstrom \& Druton, 2010). The study results largely confirms to the above said frameworks in cross cultural domain. The related concept of values is also important to the international operations of a business. Values concerns individual predispositions, while culture is concerned with entire societies. Both can and do change as societies changes (Ahlstrom \& Druton, 2010).

With globalization and expansion, overseas assignment would enhance finding employees to serve on sight and get adjusted with overseas culture by moving away from their own land., for these important positions. The MNCs should have proper strategies and policies in place to sustain their growth and survival. Managers at the Indian MNCs should remember the following guidelines as they go forward in different environment and seek to move employees to accomplish particular goals and objectives

MNCs should select expatriates who are self-confident in their knowledge skills and abilities as an expatriate who is self-confident may come across as arrogant to the host nationals. MNCs have to find the balance between confidence and arrogance. MNCs should provide their expatriate employees with an in-country network support or mentor. HR manager should be explicitly linked with overall strategic planning and should deliver the quality and quantity of leaders the company will need in the future to achieve its goals. Selection is quite important. For the firms that need to staff international locations, it's helpful to find employees who have some international experience, preferably experience in living abroad. Multiple interviews and test for cultural intelligence are helpful in determining a prospective employee's international capabilities. Similar interviews and test need to be given to foreign employees working for the firm's overseas office.

Even if the expatriate is carefully selected and given training, foreign assignments are challenging. Firms can help by giving the expatriate help in settling in, and giving aid to the expat's family with move and getting settled. Expatriate failure is costly, and a main reason for this is the family's dissatisfaction. Human resources can be used to help the firm achieve its objectives. Top management need to understand the type of workforce it seeks to build; this is particularly important when going to a new country where the slate is clean and the firm can inculcate its values among new hires.

\section{Limitations}

There are several limitations of this study. Overall, the limitations of this research are consistent with the limitations of prior empirical studies conducted in the field.

- Cross Sectional design may hamper the applicability of the causal conclusions drawn from our findings.

- The study relied on the questionnaire to collected data. Observation and Interview method is could not be carried out in the study because of the geographical distance.

- The study focused only on IT industry therefore generalization to other expatriates working in other industries should be done with care.

- There could be bias in the responses as all the responses are based on the perception of the respondents.

- Since it is a comprehensive study, exploring single construct in-depth is not feasible the study presents an overall view of expatriate adjustment and performance.

\section{Suggestion for Future}

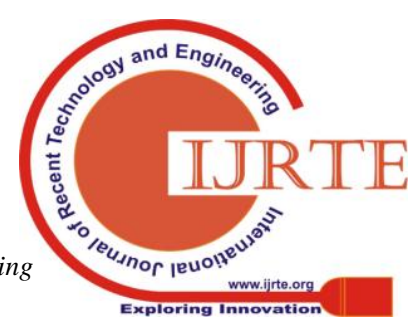




\section{Research}

Future studies must try to include to collect data from various other sources such as spouses of expatriates and children of the expatriates, colleagues, and supervisors. In the future, more instead of cross sectional study longitudinal studies must be conducted to generate rich data collected over a period of time which will give more insights in the adjustment patterns over a period of time and its impact on the study variables. Since the data was collected from the four cities, generalizability of the findings to other expatriates working in worker cities in United States of America is problematic as United States of America is a big country with many sub cultures co existing.

\section{DISCUSSION AND CONCLUSION}

A global mindset continually adapts universals of business to contextual contingencies. Since doing business globally is filled with uncertainties, amplified by numerous differences from country to country, abilities to tolerate ambiguity and to lean from new situations are critical to the global mindset (Lane \& Distefano J. J.: Maznevski, 2006). (Lane \& Distefano J. J.: Maznevski, 2006) argue that developing a global mindset requires an understanding of the relationships between people and their contexts. And one of the most important elements of the context -especially for understanding people and their behavior is culture.

Accordingly (Lane \& Distefano J. J.: Maznevski, 2006) defined global mind set as "The ability to develop and interpret criteria for personal and business performance that are independent from assumptions of a single country, culture , or context; and to implement those criteria appropriately in different countries, cultures , and contexts". The human element in the managing effectively across cultures is just as important as, and sometimes more important than, the technical or business skills. However, cross cultural interpersonal skills are less developed in IT employees than the technical or business skills.

It is felt that employees who have more experience abroad may be brought back to the parent organization so that the attachment with the organization and nation is maintained as well as the family connect is kept up. It would reinforce totally. Firms should depute those managers abroad who have put in more service these employees would be more loyal the chances of they moving out is also minimal.

Multinational IT employees who are sent on the international assignments need will need skills not always considered necessary for the domestic managers (Cullen, 2002). MNCs need to develop a rigorous selection process and use criteria that accurately predicts success. Ways of improving expatriates selection procedures would be to ensure that reliable instruments are routinely used for candidate assessment, and to identify ways in which candidate would be able to contribute to the firm's global expansion strategy. Expatriates need to be prepared to deal with all of the cultural and lifestyle changes that will be encountered abroad. The exact nature of and level of training needed should be driven, in part, by the cultural toughness of foreign location. Preparation is also needed if employees are to be successfully repatriated back to their home countries. MNCs must move towards more sophisticated repatriation programs that kick in before the expatriate has begun the foreign assignment.
Many corporations are becoming aware of the need to provide continued hands on training rather than just predaparture awarness training. An executives pre daparture training evaluation of stressors experienced abroad may be unrealistic. Without some onsite experience in the culture, executives overestimate their future ability to cope. In contrast to pre-departure training, post arrival training gives expatriates a chance to evaluate their stressors after they have encountered them. Cultural differences must be addressed when they surface in the context of working together, rather than as part of theoretical discusisons regarding why Asians and Westerners behave differently.

Though not the part of this study we realized that repatriation is also on the important problem faced by the MNCS and they should pay more attention to the process of repatriation brining the employees back home after a foreign assignment has been completed. If the employees and their families have been successfully expatriated, they become comfortable with living and working in the foreign culture. Returning home can be almost traumatic to them as was the original move abroad.

Due to globalization and intense completion on the global IT industry, the MNCS are using international assignments to remain competitive and gain edge over the competitors. The MNCs success and survival depend on its ability to develop technically qualified and self-motivated employees who are capable enough to performance in cross cultural settings. This study shows that organizations support positively effects cross cultural adjustment and the expatriate performance in the international assignment. The study also shows that the expatriate adjustment depends on the perceived family support. MNCS should also focus on the family adjustment as a whole than simply concentrating on the individual employee in the international assignments. The MNCs should facilitate smooth adjustment of the expatriate and the immediate family by providing career support, financial support and adjustment support in the host culture. Orientation programs for the accompanying spouses might ease the transition for the expatriate employee in the host culture and help in overcoming the initial cultural shock and maladjustment to the new cultural settings. If the MNCs pay little attention to the support provided, will adversely impact the expatriate cross cultural adjustment. As predicted, the empirical evidence shows that organizational support received determines the extent of cross cultural adjustment and work performance of the expatriates in international assignment. Employees' perceptions of the organization's dedication to their well-being in light of support and career planning contribute to enhancing expatriates' work adjustment. This study shows the contribution of the individual competencies like emotional, cultural intelligence and organizational support on expatriate performance.

\section{REFERENCES}

1. Ahlstrom, D., \& Druton, G. D. (2010, International management strategy and culture in the emerging world. Mason, USA: South-Western Cenage Learning.

2. Chen, A. S., Lin, Y., \& Sawangpattanakul, A. (2011), International Journal of Intercultural Relations The relationship between cultural intelligence and performance with the mediating effect of culture shock: A case from Philippine laborers in Taiwan. International Journal of Intercultural Relations, 35(2), 246-258. 
Impact of Emotional intelligence, cultural intelligence, Perceived organizational supporting practices and Perceived family support on cross cultural adjustment of Indian IT expatriates working in the United States of America

doi:10.1016/j.ijintrel.2010.09.005

3. Ghauri, P., \& Gronhaug, K. (2005), Research methods in business studies (3 ed.). England: Prentice Hall Financial Times.

4. Hair, J. F., Black, W., Babin, B. J., \& Anderson, R. (2010), Multivariate data analysis: A global prespective (Seventh ed.). Delhi: Pearson.

5. Hechanova, R., Beehr, T. A., \& Christiansen, N. D. (2003), Antecedents and Consequences of Employees Adjustment to Overseas Assignment : A Meta-analytic Review, 52(2), 213-236.

6. Kothari, C. R., \& Garg, G. (2013), Research Methodology. New Delhi, India: New Age International Publishers.

7. Kraimer, M. (2004), An Examination of Perceived Organizational Support as a Multidimensional Construct in the Context of an Expatriate Assignment. Journal of Management, 30(2), 209-237. doi:10.1016/j.jm.2003.01.001

8. Lane, H. W., \& Distefano J. J.: Maznevski, M. L. (2006), International management behavior: text, readings, and cases (5 ed.). Malden, MA, USA: Blackwell Publishing

9. Lazarova, M. (2011), A model for the influence of social interaction and social support on female expatriates ' cross- cultural adjustment A model for the in uence of social interaction and social support on female, 5192(November 2015). doi:10.1080/09585190210125903

10. Maylor, H., \& Blackmon, k. (2005), Researching business and management. London: Palgrave macmillian.

11. Osman-gani, A. M., \& Rockstuhl, T. (2008), Antecedents and Consequences of Social Network Characteristics for Expatriate Adjustment and Performance in Overseas Assignments: Implications for HRD, 7(1), 32-57. doi:10.1177/1534484307312182

12. Wong, C. S., \& Law, K. S. (2002), The effects of leader and follower emotional intelligence on performance and attitude:An exploratory study. The Leadership Quarterly, 13, 243-274.

13. Wua, P. C., \& Ang, S. H. ( 2011), Singapore, The impact of expatriate supporting practices and cultural intelligence on cross-cultural adjustment and performance of expatriates in Singapore. The International Journal of Human Resource Management, 22(13), 2683-2702

14. Zikmund, G. W. (2003), Business research methods. New Delhi: CENGAGE learning. 